\title{
Media Subjugating Public Health amidst Covid-19
}

\author{
Jaiswal $\mathrm{AK}^{1 *}$, Chaurasia $\mathrm{H}^{2}$ and Mishra $\mathrm{A}^{1}$ \\ ${ }^{1}$ International Institute for Population Sciences, India \\ ${ }^{2}$ Indira Gandhi National Open University, India
}

Perspective

Volume 4 Issue 6

Received Date: October 20, 2020

Published Date: November 03, 2020

DOI: $10.23880 /$ eij-16000164

*Corresponding author: Ajit Kumar jaiswal, Ph.D. Scholar, International Institute for Population Sciences, Mumbai, India, Email: ajitjaiswal20@gmail.com

\section{Abstract}

Sound health is the penultimate source of one's sustainable existence. However with the widespread of unparalleled pandemic as COVID-19, the negative impact to the health becomes pervasive. Furthermore growing modernization further enhances the likelihood of health influencing factors. One of such factors is "Media". This article thus seeks to assess and assimilate the impact of media throughout the beginning and the widespread of coronavirus. Media which could turn out to be effective in regulating public health or at least help controlling the widespread in the long run, turned out to be the medium of spreading its aftermaths. While the pandemic's ill effects continued to grasp everyone, the media too functioned in ways which were far beyond helping. All the efforts that media put in, were rather directed towards their personal gain of popularity and TRP than public welfare. Thus while COVID-19 functioned primarily at affecting the physical health, media in lots of different ways, functioned to affect the mental health.

Keywords: Social Media; COVID-19; Corona-Virus; Lockdown; Depression; Aggression; Mental Health; Public Health

Abbreviations: SARSS-COV2: Severe Acute Respiratory Syndrome Coronavirus 2.

\section{Introduction}

Sound health for all is a rudimentary necessity for all. Thus to recognize a person as of sound health, it mandates him/her to be healthy on all plains i.e. physically, mentally and emotionally. Yet despite its thorough vitality the concept of "Health is Wealth" seems to be deflecting from its purposefulness entirely. To witness this fact, a minor observation around, or given the situation, mere contemplation might validate this point: COVID-19. A term of medical origin warping the minds and even in many cases the bodies, of every man, woman and child, coming in its close proximity. The origin of COVID-19 is attributed to severe acute respiratory syndrome coronavirus 2 (SARSSCOV2), emerging in the city of Wuhan, China [1]. And from there on moving to coil the whole world in the strings of its dreadfulness. The widespread of the virus knew no bounds, claiming the lives of thousands on a day-to-day basis, thus leaving nothing else for the people to forestall their attention to. The people being infected by it suffered with wide range of diseases ranging from mild issues (such as cough, fever, tiredness, sore throat, loss of taste and smell, etc), to severe (such as chest pain and pressure, difficulty in breathing, and loss of speech and movement).

The aftermaths of the virus however weren't just confined to physical level. To add to it were the mental and psychological effects of the virus as well, pushing people to the verge of breakdown, due to the fear of loss of their lives and the lives of their loved ones. In the absence of vaccine or even any other preventive measure, the precautionary lockdown served as only viable measure to attenuate the virus [2]. A nationwide lockdown throughout the affected countries, severing all the physical connection from the outside world, forced people into their houses which eventually began taking toll on them. WHO along with public health authorities across the globe emphasized upon the 


\section{Epidemiology International Journal}

nationwide lockdown, with primary measures focusing on social distancing, self-isolation, to contain the rapid spread of the COVID-19 outbreak [3].

\section{The Media Widespread}

The mandatory and necessary house confinement especially owing to a pandemic, left people with no choice but to stick to the media sources for the obvious reason of getting regular update over the severity of such an unparalleled atrocious circumstance, other than passing their spare time. The media identifying their role and responsibility thus came forth to ensure the incessant digital interaction with the outside world, especially pertaining to the COVID-19 updates. Thus each and every media sources began flooding with the minute by minute update of not just the widespread and the hiking death tolls but also with every possible update over the virus they could get their hands onto.

The increased accountability of the media led to hike of the dependency of people over them, recording $68 \%$ of the global population using media for corona updates alone [4]. The rising concern for the corona and the uprising curiosity was met by the media who entirely took it upon them to meet the informative need of the time. Thus eventually their updates over the coronavirus shifted from being honest and qualitative to highly quantitative. Media started feeding people with all sorts of information they came across, merely to feed the ongoing demand of coronavirus update. This, thus in turn gave rise to uncorroborated or even the misinformation throughout the media platforms, giving birth to conspiracy theories, fake news and misleading information [5].

\section{Truthful Fallacy}

The outreaching misleading and fake information became detrimental in exposing public health to dire ripple effect of the COVID-19 with media, as its mouthpiece. The media strategy of impacting the people with the quantity of updates for their personal gain of popularity resulted in intermingling of the information and misinformation with barely any possibility of knowing the difference. Such uncorroborated theories, hoaxes and misinformation merely to feed the growing curiosity and to fill the void of people's otherwise spare time, also ensured long lasting impact over people's mind of such fake news. Guy Berger the Director for Policies and Strategies regarding Communication and Information at UNESCO remarked, "In a time of high fears, uncertainties and unknowns, there is fertile ground for fabrications to flourish and grow. The big risk is that any single falsehood that gains traction can negate the significance of a body of true facts" [6].
Apparently this is what followed; with the blurred line between myths and facts, the lack of faith over the true information or the belief over the false one rose. Consequently, the fear of the incurability of the pandemic, reactions to the fake news, and fear of cumbersome truth challenged people's mental peace and tranquility. Media's round the clock supply of "news and updates", whether verified or not, severely and equally challenged people's mental health, pushing them to the brink of constant anxiety and insecurity. This hence resulted in diverse range of mental issues ranging from panicking behaviour, frequently getting anxious or collective hysteria to pervasive feeling of hopelessness, helplessness, and desperation with consequent result of imbuing suicidal tendencies [7].

\section{Unwieldy Truth}

Furthermore the continuous feeding of, even the truth hampered the mental health of the people as well. The flood of both local and global COVID-19 updates, of not just hiking cases but deaths; that too in the absence of any remedy or cure, turned out to be equally depressing and mind numbing. This was further incinerated by media's uplifting of their telecast to the loss of daily basis livelihoods and the death caused by these. The narratives of the devastating horrors and pains suffered by the trauma survivors, and its telecast, further elevated the agony of survivors along with others [8].

However even if one was to regard the media policy of continuous news, in the public interest, their unchecked and uncontrolled telecast, caused it to backfire. At first, it hindered the adaptation to the new-normal, people had no choice but to adjust to. Second, the extent of atrocity of the telecast, if intended to keep people in check, reached its saturation point, thereby serving no purpose of preventing people's careless action. Thus with the withdrawal of the lockdown (even partially), made people rush back to their old life, against all odds of COVID-19; only being protected by sanitizers and face mask, making all the efforts of socialdistancing futile. Being completely fed with watching the horrors of COVID-19 people rushed towards their old lives thereby undermining the positive intention (if any) of the media to help control the widespread.

\section{Conclusion}

The media, throughout the atrocity could have played a more responsible role. Instead of going after the quantity of news for the popularity and TRP, a planned and regulated telecast of all the updates would have laid a positive impact. Which however in this case, made people used to the horrors and fed up with witnessing it, thus seeking refuge from these telecasts by rushing carelessly back to their old normal . 


\section{Epidemiology International Journal}

\section{References}

1. Shereen MA, Khan S, Kazmi A, Bashir N, Siddique R (2020) COVID-19 infection: Origin, transmission, and characteristics of human coronaviruses. Journal of Advanced Research 24: 91-98.

2. Serafini G, Parmigiani B, Amerio A, Aguglia A, Sher L, et al. (2020) The psychological impact of COVID-19 on the mental health in the general population. QJM An International Journal of Medicine 113(8): 531-537.

3. Ammar A, Trabelsi K, Brach M, Chtourou H, Boukhris O, et al. (2020) Effects of home confinement on mental health and lifestyle behaviours during the COVID-19 outbreak: Insight from the" ECLB-COVID19" multi countries survey. MedRxiv.
4. Datta R, Basu T (2020) Infodemic with Misinformation and Disinformation in Pandemic COVID-19 Situation: A Global Case Study.

5. Zhou P, Yang XL, Wang XG, Hu B, Zhang L, et al. (2020) A pneumonia outbreak associated with a new corona virus of probable bat origin. Nature 579: 270-273.

6. (2020) During this coronavirus pandemic, fake news is putting lives at risk: UNESCO, Pina.

7. Thakur V, Jain A (2020) COVID 2019-suicides: a global psychological pandemic. Brain Behaviour Immun 88: 952-953.

8. McCann L, Pearlman LA (1990) Vicarious traumatization: A framework for understanding the psychological effects of working with victims. J Trauma Stress 3: 131-149. 